\title{
Deduzindo a fórmula para cálculo de diagonais de um polígono: uma experiência no Ensino Fundamental
}

\author{
Inferring the formula for diagonal calculation of a polygon: an elementary \\ school study
}

- Camila Dorneles da Rosa',

José Carlos Pinto Leivas²,

Mauricio Ramos Lutz ${ }^{3}$,

Jussara Aparecida da Fonseca ${ }^{4}$

\section{RESUMO}

Este artigo apresenta uma investigação resultante de ações do Grupo de Estudos e Pesquisas em Geometria do Programa de Pós-Graduação em Ensino de Ciência e Matemática da Universidade Franciscana, a qual teve por objetivo verificar se a utilização de materiais manipuláveis e atividades exploratórias possibilitam a construção de conceitos e a dedução de fórmulas matemáticas, em particular, relacionados às diagonais de polígonos. A metodologia utilizada para a pesquisa é de natureza qualitativa e a prática de ensino foi desenvolvida junto a um grupo de alunos do $8^{\circ}$ e $9^{\circ}$ anos do Ensino Fundamental, de uma escola pública no município de Manoel Viana/RS. Os resultados mostraram que, para o grupo participante, o material construído favoreceu a identificação dos elementos dos polígonos e as atividades exploratórias comprovaram que é possível desenvolver estratégias para conduzir os alunos à dedução de resultados matemáticos, permitindo-lhes compreender os elementos envolvidos em uma dada expressão, desmitificando o processo de apresentação de fórmulas prontas.

Palavras-chave: Polígonos. Materiais manipuláveis. Atividades exploratórias.

1 Universidade Franciscana | camiladornelesdarosa@gmail.com

2 Universidade Franciscana | leivasjc@unifra.br

3 Instituto Federal Farroupilha - Campus Alegrete | mauricio.lutz@iffarroupilha.edu.br

4 Instituto Federal Farroupilha - Campus Alegrete | jussara.fonseca@iffarroupilha.edu.br 


\title{
Deduzindo a fórmula para cálculo de diagonais de um polígono: uma experiência no Ensino Fundamental
}

\author{
Inferring the formula for diagonal calculation of a polygon: an elementary \\ school study
}

\section{ABSTRACT}

This article presents an investigation by Geometry Research and Study Group from Postgraduation Program in Science and Mathematics from Universidade Franciscana. The study aimed to verify whether the use of manipulatives and exploratory activities enable the construction concepts and the deduction of mathematical formulas in diagonal of polygons. The methodology applied in this study was qualitative. The teaching practice was developed with 8th and 9th grade elementary school students from a public school in Manoel Viana/RS. The results showed that the constructed material improved the identification of the polygons elements, and the exploratory activities proved that it is possible to develop strategies to lead students in deducting mathematical results. This way, it allowed them to understand the elements involved in a given expression, demystifying the presentation of ready-made formulas.

Keywords: Polygons. Manipulative Materials. Exploratory Activities. 


\section{Introdução}

Conhecimentos geométricos estão relacionados a diversos contextos do nosso cotidiano. 0 reconhecimento de formas geométricas, a percepção e localização espacial, a determinação de medidas de comprimento, superfície e capacidade são algumas das habilidades propiciadas a partir dos conhecimentos geométricos.

Nesse sentido, Carvalho e Carvalho (2011, p. 3) apontam que

a geometria pode desenvolver habilidades ligadas à forma, espaço, distância, percepção entre outros, permitindo uma maneira de compreender, descrever e representar organizadamente, o mundo no qual vivemos, bem como estabelecer aplicações práticas nas atividades cotidianas.

Na mesma direção, Bulos (2011, p. 5) apresenta a Geometria como uma possibilidade para 0 desenvolvimento de "habilidades e competências necessárias para a resolução de problemas do nosso cotidiano, visto que o seu entendimento nos proporciona o desenvolvimento da capacidade de olhar, comparar, medir, adivinhar, generalizar e abstrair".

Sobre a formação de conceitos geométricos, Usiskin (1994) salienta que esta ocorre conforme uma das quatro dimensões da Geometria. A primeira dimensão faz referência à Geometria como estudo da visualização, do desenho e da construção de figuras; a segunda encara a Geometria como o estudo do mundo real (físico); a terceira dimensão a considera um meio para representação de conceitos matemáticos, ou outros, cuja origem não é visual ou física; e a quarta dimensão concebe a Geometria como exemplo de um sistema matemático organizado.

As diferentes perspectivas relacionadas à Geometria apontam para os múltiplos entendimentos que os sujeitos podem apresentar sobre os conhecimentos geométricos, bem como para os diversos objetivos e justificativas relacionados ao ensino e à aprendizagem dessa área do conhecimento.

De acordo com a Base Nacional Comum Curricular (BNCC), o desenvolvimento de conhecimentos geométricos na Educação Básica, em particular no Ensino Fundamental, deve envolver "o estudo de um amplo conjunto de conceitos e procedimentos necessários para resolver problemas do mundo físico e de diferentes áreas do conhecimento" (BRASIL, 2017, p. 267).

Assim, percebemos que a construção dos conhecimentos geométricos, no âmbito escolar, vai além dos conteúdos relacionados à área específica. Isso se deve ao fato da Geometria possibilitar interligar outras áreas da própria Matemática, como Aritmética e Álgebra, elucidando diferentes conceitos e propriedades.

Com a intenção de contribuir com reflexões sobre o ensino e aprendizagem de conceitos geométricos, foi criado o Grupo de Estudos e Pesquisas em Geometria (GEPGEO), vinvulado ao Programa de Pós-Graduação em Ensino de Ciência e Matemática da Universidade Franciscana (UFN), o qual realiza estudos e investigações, visando colaborar com melhorias no processo de ensino e aprendizagem de Geometria em diferentes níveis de escolaridade.

Este trabalho é produto de uma das ações do GEPGEO, a qual consistiu-se em uma investigação realizada com alunos dos anos finais do Ensino Fundamental de uma escola do município de Manoel Viana/RS. 0 mesmo teve por objetivo verificar se a utilização de materiais manipuláveis e atividades exploratórias possibilitam a construção de conceitos e a dedução de fórmulas matemáticas, em particular, relacionadas às diagonais de polígonos.

No que segue, apresentamos algumas considerações a respeito da utilização de materiais didáticos no ensino de Matemática, bem como elucidamos a forma de organização da investigação realizada e a análise e discussão dos resultados encontrados. 


\section{0 uso de materiais didáticos no ensino de Matemática}

Diferentes instrumentos pedagógicos tais como o livro didático, a calculadora, o quadro-negro, o giz, os softwares, entre outros, podem ser compreendidos como recursos ou materiais didáticos. Diariamente, esses e outros recursos são utilizados por professores para preparar, implementar e avaliar o processo de ensino, com o objetivo de promover a aprendizagem de matemática.

Para Pais (2000, p. 2-3),

os recursos didáticos envolvem uma diversidade de elementos utilizados como suporte experimental na organização do processo de ensino e de aprendizagem. Sua finalidade é servir de interface mediadora para facilitar na relação entre professor, aluno e o conhecimento em um momento preciso da elaboração do saber.

Zabala (1998, p. 167) compreende materiais didáticos de forma ampla, denominando-os de materiais curriculares ou materiais de desenvolvimento curricular. Para o autor, são definidos como todos os "instrumentos que proporcionam ao educador referências e critérios para tomar decisões, tanto no planejamento como na intervenção direta no processo de ensino/aprendizagem e em sua avaliação".

Para esclarecer a função dos materiais curriculares, bem como classificá-los, o autor faz uso de quatro critérios. 0 primeiro critério refere-se aos diferentes âmbitos de intervenção docente, 0 que acarreta a existência de materiais relacionados a todo o sistema educativo, ao âmbito geral da escola ou à sala de aula. 0 segundo, diz respeito à intencionalidade ou função, ou seja, a finalidade do uso do material curricular, que pode ser: orientar, guiar, exemplificar, ilustrar, propor e divulgar. 0 critério seguinte associa os conteúdos e a maneira de organizá-los. Por fim, o último critério está relacionado à classificação, conforme o suporte que o material curricular pode oferecer.

Lorenzato (2009) ressalta que o professor deve se questionar sobre o motivo de empregar determinado material, de que forma ele pode ser utilizado: apresentar um assunto, motivar os alunos, auxiliar a memorização de resultados ou facilitar a redescoberta pelos alunos. Ao definir seu propósito, o professor poderá escolher o material mais eficaz para cada momento da aula.

Sendo assim, para que o uso de materiais didáticos possa auxiliar na aprendizagem matemática, é necessário o professor ter objetivos bem claros e definidos, entre eles aqueles relacionados à intencionalidade da aplicação de determinado material e aos conceitos a serem construídos.

Partindo dos pressupostos apresentados, o GEPGEO elaborou uma definição de materiais didáticos, ao afirmar que "são todos os recursos materiais que podem ser utilizados pelo professor, de forma intencional, explorados pelos estudantes e que propiciem sua construção do conhecimento" como explicitado por Leivas, Lara e Soares (2017, p. 211).

Entre os possíveis materiais didáticos que podemos utilizar, encontramos os concretos ou manipuláveis, os quais, de acordo com Camacho (2012, p. 23), podem ser definidos como:

[...] objetos didáticos intuitivos e dinâmicos que visam a compreensão de diversos conceitos, tendo como finalidade, motivar e auxiliar o aluno na concretização das tarefas propostas, em qualquer fase de desenvolvimento, onde, através do contato direto com o objeto, o aluno entrega-se intuitivamente ao processo de descoberta, adquirindo destrezas na interiorização, estruturação e compreensão de conceitos.

Por esse viés, entendemos que, em um espaço no qual se utiliza material concreto, o aluno necessita de tempo para descobrir relações por meio da experimentação. 0 professor, nesse processo, passa a exercer o papel de observador e mediador desse conhecimento, intervindo, questionando e direcionando quando necessário. 
Dessa forma, quando o docente decide pela utilização de determinado material concreto ou manipulável, cabe a ele a conexão entre o material a ser utilizado, o conhecimento matemático que se deseja construir e os sujeitos a que se destinam. Como apontam Rêgo e Rêgo (2013, p. xxv), o professor dentro desse processo tem a função de promover e incentivar a realização das atividades, intermediando ao lado do material concreto e das atividades realizadas o conhecimento trazido pelo aluno e o conhecimento novo a ser desenvolvido.

Outra característica importante do uso de materiais manipuláveis é a promoção da interação entre aluno-aluno e aluno-professor. Sobre isso, Januário (2008, p. 38) afirma que "esses recursos contribuem para a socialização dos alunos, promovendo a integração e a participação ativa nas atividades propostas".

Nesse sentido, se o material didático escolhido for adequado aos objetivos a serem alcançados e ao público-alvo a que se destinam, sua utilização pode favorecer a atuação discente no processo de ensino e aprendizagem de forma mais dinâmica e efetiva.

Com base nos argumentos expostos, acreditamos que a utilização de materiais didáticos, se realizada de forma bem planejada, dentro dos critérios do âmbito de intervenção, da intencionalidade e dos conteúdos, pode se tornar um bom estímulo na construção dos conhecimentos matemáticos e aprendizagem dos alunos.

\section{Encaminhamentos metodólogicos}

A presente investigação, de caráter qualitativo, foi desenvolvida a partir da aplicação de uma oficina, planejada pelos membros do GEPGEO e elaborada a partir da utilização de dois recursos didáticos: polígonos regulares construídos com fitas de papel e atividades exploratórias.

A atividade prática teve duração aproximada de quatro horas e foi realizada com um grupo de nove alunos participantes do Programa Novo Mais Educação ${ }^{1}$ da Escola Estadual de Ensino Fundamental Salgado Filho, localizada no município de Manoel Viana/RS. Doravante, para garantir o anonimato, os sujeitos partícipes serão indicados por aluno A, B, C, D, E, F, G, H e I.

A oficina foi dividida em três momentos e teve por objetivos: construir polígonos regulares com fitas de papel, identificar elementos principais de polígonos regulares; compreender o conceito de diagonal de um polígono; identificar e representar as diagonais de um polígono e determinar uma fórmula geral para o cálculo do número de diagonais de um polígono convexo de $n$ lados.

0 primeiro momento foi destinado à construção dos polígonos regulares com fitas de papel. Como o tempo para realização da prática era restrito, realizamos a construção de apenas quatro polígonos regulares: triângulo, quadrado, pentágono e hexágono. Iniciamos construindo os polígonos regulares com número ímpar de lados (triângulo e pentágono), pois necessitavam de apenas uma fita. Na Figura 1, estão ilustrados os passos necessários para a construção desses polígonos.

10 Programa Novo Mais Educação, criado pela Portaria MEC nº 1.144/2016 e regido pela Resolução FNDE nº 17/2017, é uma estratégia do Ministério da Educação que tem como objetivo melhorar a aprendizagem em língua portuguesa e matemática no ensino fundamental, por meio da ampliação da jornada escolar de crianças e adolescentes, otimizando o tempo de permanência dos estudantes na escola. 
Figura 1 - Construção dos polígonos regulares de 3 e 5 lados

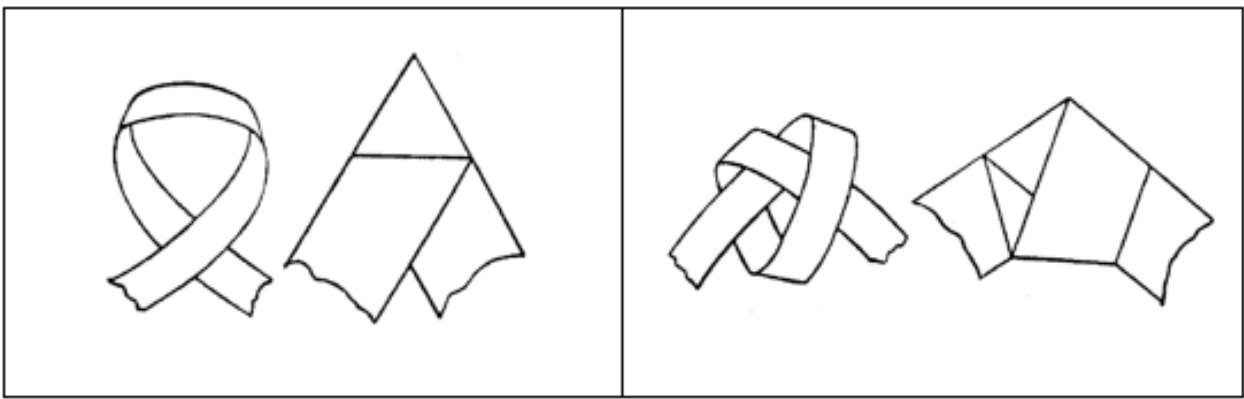

Fonte: Miranda (1993, p. 18)

Após essa primeira etapa, realizamos a construção dos polígonos regulares com duas fitas, que correspondiam àqueles com número par de lados (quadrado e hexágono). Na Figura 2, apresentamos os passos da construção dos dois polígonos.

Figura 2 - Construção dos polígonos regulares de 4 e 6 lados

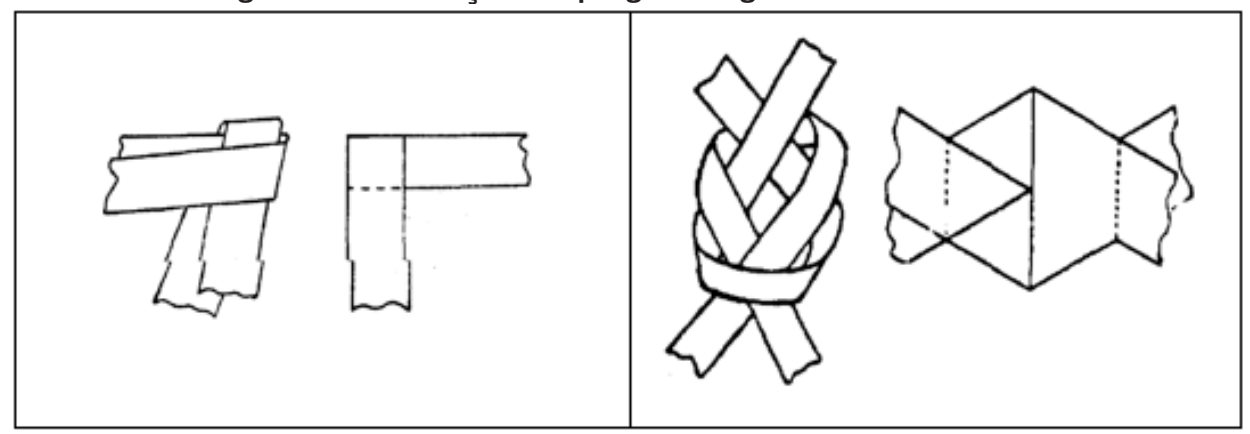

Fonte: Miranda (1993, p. 19)

O segundo momento foi destinado à exploração dos polígonos construídos, com a finalidade de identificar alguns de seus elementos. Essa etapa foi realizada a partir de três atividades: a primeira consistiu-se em completar um quadro com a nomenclatura e o número de lados, vértices e ângulos de cada polígono; a segunda questionou o quantitativo de diagonais do quadrado e do hexágono; e a última solicitou uma definição intuitiva de diagonal a partir das observações feitas.

No terceiro momento da oficina, os alunos foram instigados a deduzir uma expressão matemática que pudesse determinar o número de diagonais de um polígono regular convexo de $n$ lados. Para essa etapa, foram utilizadas seis atividades, nas quais, ao observarem regularidades, deveriam deduzir uma expressão matemática que pudesse ser utilizada para a determinação do número de diagonais de qualquer polígono. A primeira questionava qual polígono não possuía diagonal e a justificativa. A segunda compreendia o preenchimento de um quadro com informações sobre o número de diagonais que partem de cada vértice de um polígono de 4, 5 e 6 lados. A seguinte, indagava sobre a relação entre o número de diagonais concorrentes em cada vértice e o número de lados do polígono. $\mathrm{A}$ quarta atividade perguntava o número de diagonais de um polígono de 7, 8, 9, 10, 20 e $n$ lados. A quinta e a sexta atividades se complementavam com questionamentos investigativos, de forma a conduzir o participante a obter a fórmula para o cálculo do número de diagonais de um polígono regular convexo de $n$ lados. 


\section{Análise das atividades e discussão dos resultados}

Iniciamos a oficina construindo polígonos regulares com 3, 4, 5 e 6 lados, utilizando fitas de papel pardo. Esse material foi escolhido tendo em vista seu baixo custo e sua presença na maioria das escolas. Além disso, é um tipo de papel que apresenta certa durabilidade, o que permite explorações futuras do material construído. Na Figura 3, apresentamos os alunos realizando suas construções.
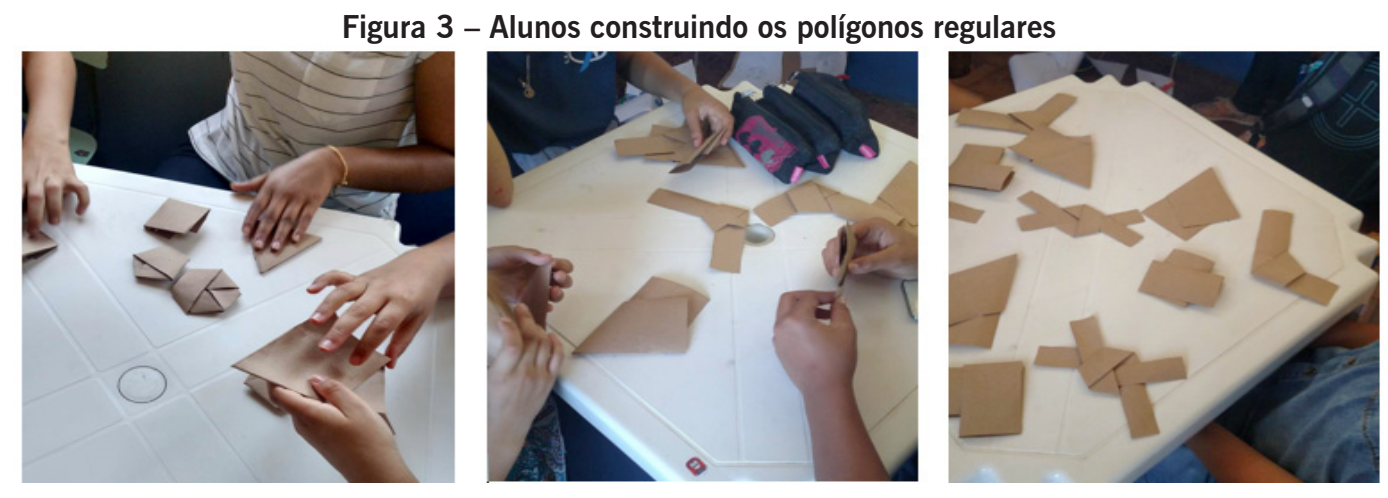

Fonte: acervo dos autores (2017)

Destinamos para essa fase cerca de uma hora, durante a qual os alunos trabalharam com afinco para a obtenção de seus polígonos. Durante todo o processo, eles se mostraram empenhados e concentrados para a realização da construção e, à medida em que iam finalizando, auxiliavam os colegas com mais dificuldades.

Acreditamos que essa fase de construção vai ao encontro das potencialidades da utilização de material concreto destacadas por Rêgo e Rêgo (2013, p. xxv), ao afirmarem que:

[...] por meio de experiências realizadas com material concreto, o aluno desenvolve o gosto pelo prazer da descoberta, para enfrentar desafios e vencê-los, desenvolvendo hábitos e costumes que podem conduzi-lo, mais tarde, a ser autônomo e capacitado a agir.

Após a construção desses quatro polígonos regulares, os alunos exploraram o material e passaram à segunda etapa da oficina. Inicialmente, eles completaram um quadro com informações sobre cada um dos polígonos construídos, conforme exemplificamos na Figura 4.

Figura 4 - Resposta apresentada pelo Aluno I

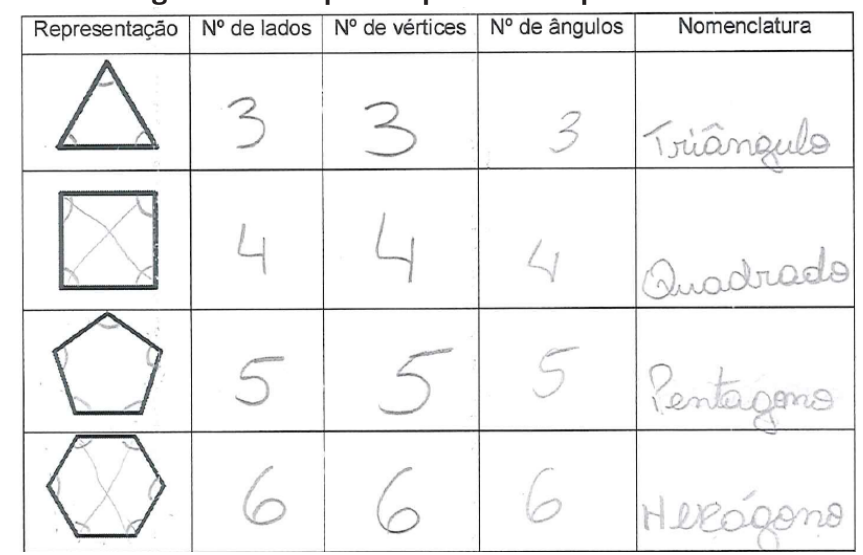

Fonte: acervo dos autores (2017) 
Observamos que os alunos não apresentaram dificuldades na resolução da primeira atividade, pois todos os participantes completaram o quadro de forma correta demonstrando ter conhecimento sobre polígonos e seus elementos principais (lados, vértices e ângulos).

Dando prosseguimento, passamos para a segunda atividade, a qual questionava sobre o número de diagonais de um quadrado e de um hexágono, sendo que deveriam determinar tais valores, explorando os polígonos construídos. Depois que cada aluno determinou o número de diagonais dos respectivos polígonos regulares, deveriam elaborar uma definição para este conceito (terceira atividade).

Incentivamos essa realização da escrita na aula de Matemática por acreditar que tal prática auxilia na aprendizagem, como ressaltado por Santos (2005, p. 129) ao afirmar que "[...] a escrita nas aulas de Matemática atua como mediadora, integrando as experiências individuais e coletivas na busca da construção e apropriação dos conceitos abstratos estudados".

Em relação ao número de diagonais do quadrado, todos os alunos acertaram, porém o mesmo não ocorreu quanto ao número de diagonais do hexágono. Quatro alunos indicaram que o hexágono possui oito diagonais e os demais indicaram, em suas respostas, valores entre duas e sete diagonais, evidenciando falta de clareza em relação ao conceito de diagonal. Outra possibilidade que conjecturamos para a determinação errônea do quantitativo de diagonais é a falta de concentração e organização para contagem das diagonais do hexágono ou, até mesmo, o registro incorreto dos dados observados a partir da manipulação do material.

Para analisar as respostas quanto à definição de diagonal, que correspondia à terceira atividade dessa etapa, lançamos mão de Dulce e Pompeo (1995), que definem diagonal de um polígono como "um segmento cujas extremidades são vértices não consecutivos do polígono." (p. 136).

Percebemos pelas respostas apresentadas que, mesmo os alunos não conseguindo apresentar uma escrita formal da definição de diagonal, davam indicativos de uma noção intuitiva desse conceito matemático. Três alunos, B, C e G, desenharam uma figura para representar a noção de diagonal. $\mathrm{Na}$ Figura 5, apresentamos as construções desses alunos.

Figura 5 - Respostas dadas pelos alunos B, G e C, respectivamente

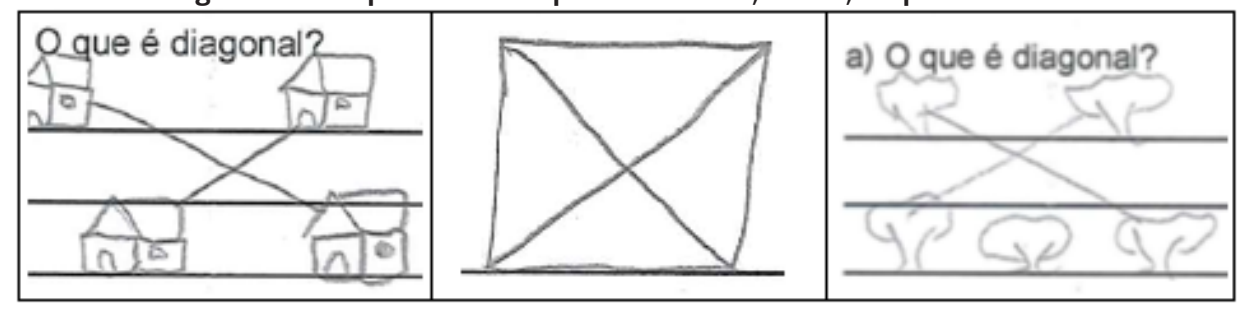

Fonte: acervo dos autores (2017)

Por sua vez, os demais alunos tentaram formalizar, por escrito, uma definição para diagonal, como apresentamos no Quadro 1.

Quadro 1 - Respostas dadas pelos alunos A, D, E, F, H e I.

\begin{tabular}{|l|l|}
\hline Aluno & Resposta apresentada \\
\hline A & É pular um vértice e passar para o seguinte. \\
\hline D & É que tem que pular um vértice para ir para outro vértice sendo assim forma a diagonal. \\
\hline E & É um ângulo que não está na vertical nem na horizontal, um meio termo. \\
\hline F & Uma reta que vai para outra. \\
\hline H & É quando passa de um vértice para o outro. \\
\hline I & Diagonal é o segmento para ligar um ponto ao outro. \\
\hline
\end{tabular}


Analisando o Quadro 1, observamos que, para os alunos A, D e H, os verbos "pular" e "passar" têm o sentido de desconsiderar o vértice consecutivo, aproximando-se da definição formal que apresentamos anteriormente. Por sua vez, o aluno I entende a noção da diagonal como um segmento de reta, mas não faz referência aos vértices não consecutivos. Já os alunos $E$ e $F$ registram definições confusas, que não representam o conceito de diagonal.

A importância do aluno conseguir escrever uma definição para um conceito matemático, a partir do que compreendeu sobre ele, reside no fato desta prática indicar o quanto ele domina tal conceito, pois "um estudante que compreende e domina um determinado conceito deve ser capaz de escrever sobre ele, ressaltando suas certezas e possíveis dúvidas" (SANTOS, 2005, p. 128).

Após os alunos realizarem as três atividades da segunda etapa da oficina, discutimos, no grande grupo, o conceito de diagonal, utilizando como material de apoio os polígonos construídos com fitas de papel. Após a formalização do conceito de diagonal, prosseguimos com a oficina passando para o terceiro momento, o qual iniciou com a quarta atividade, que questionava sobre qual polígono não possui diagonal e respectiva justificativa. Todos os alunos responderam corretamente que é o triângulo o polígono que não apresenta diagonais, justificando informalmente que isso ocorre por ser o polígono que não apresenta vértices não consecutivos. Na Figura 6 , apresentamos a resposta dada pelo aluno $A$, na qual percebemos a ideia intuitiva de que, para ser diagonal, é necessário ser um segmento de reta que liga vértices não consecutivos.

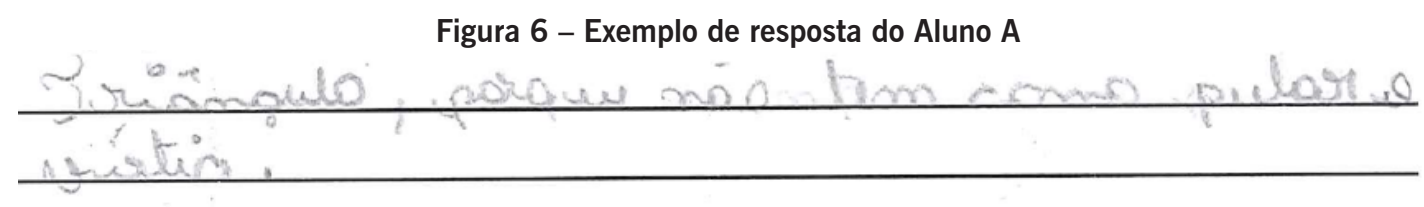

Fonte: acervo dos autores (2017)

Para a quinta atividade, os alunos deveriam explorar o quadrado, o pentágono e o hexágono construídos e completar um quadro em que era questionado o número de diagonais presentes em cada um dos vértices desses polígonos. A Figura 7 apresenta a resposta elaborada pelo aluno G, a qual está correta, assim como dos demais participantes.

Figura 7 - Resposta do Aluno G

\begin{tabular}{|c|c|c|}
\hline Número de lados & Número de diagonais que partem de um vértice & \\
\hline 4lados & 9 & $4-1=$ \\
\hline 5 lados & 2 & $5-2$ \\
\hline 6lados & 3 & $6-3=3$ \\
\hline
\end{tabular}

A partir do preenchimento do quadro, foi indagada a relação existente entre o número de diagonais que partem de um vértice e o número de lados de um polígono, o que correspondeu à sexta atividade. Dos nove participantes, seis observaram que o número de diagonais, partindo de um mesmo vértice, correspondia ao número de lados do polígono diminuído de 3 unidades. Dois alunos não apresentaram resposta e o outro aluno respondeu que "cada vez que aumenta os lados cresce o número dos vértices". Pela resposta ou ausência delas, percebermos que esses três alunos não compreenderam o que estava sendo solicitado.

Para verificar se esse resultado era válido para outros polígonos, os alunos passaram para a sétima atividade, a qual consistia em determinar o número de diagonais por vértice de polígonos de $8,9,10,20$ e $n$ lados, agora sem o apoio do material concreto. Buscávamos, com essa atividade, 
verificar se os alunos determinariam, a partir da observação da regularidade presente nos casos analisados, que para cada polígono de $n$ lados, o número de diagonais concorrentes em cada vértice é dado por $(n-3)$.

Observamos que os seis alunos, que responderam corretamente a atividade anterior, concluíram com êxito essa etapa. Em contrapartida, os outros três não completaram a atividade de modo correto, demonstrando não terem conseguido visualizar uma regularidade na relação entre o número de lados do polígono e o número de diagonais concorrentes em cada vértice. Na Figura 8, exemplificamos uma resolução possivel, essa apresentada pelo aluno $\mathrm{B}$.

Figura 8 - Resposta do Aluno B

\begin{tabular}{|c|c|}
\hline Número de lados & Número de diagonais que partem de um vértice \\
\hline 8 lados & 5 \\
\hline 9 lados & 6 \\
\hline 10 lados & 7 \\
\hline 20 lados & 17 \\
\hline$\ldots$ & $N-3$ \\
\hline nlados & $\cdots$ \\
\hline
\end{tabular}

Fonte: acervo dos autores (2017)

A oitava atividade constituiu-se na análise dos dados preenchidos no quadro da atividade anterior, de modo a determinar o número total de diagonais em um polígono regular convexo de $n$ lados. Nessa etapa, esperávamos que os alunos concluíssem que, se um polígono tem $n$ lados, logo tem $n$ vértices, e se de cada vértice partem $(n-3)$ diagonais, então o polígono apresenta $n \times(n-3)$ diagonais. Essa expressão ainda não é a que determina o número de diagonais de um polígono, contudo, deduzíla faz parte do processo para determinação da expressão final.

Essa atividade dependia da anterior e, por tal razão, apenas os seis alunos que conseguiram chegar à generalização do número de diagonais por vértice do polígono conseguiram realizá-la. Apesar de os alunos compreenderem que a relação existente consistia na multiplicação do número de diagonais em cada vértice pelo número de vértices, não conseguiram representar a expressão totalmente correta, apresentando respostas tais como: $n-3 \times n$ e $n-3 \times(n)$.

Ao questionarmos os alunos a respeito da ordem das operações na resolução da expressão $n-3 \times(n)$, eles responderam que primeiro deveria ser determinado o valor de $(n-3)$ e depois esse resultado seria multiplicado por $n$. Notamos que os alunos demonstraram saber o que deveria ser feito, mas não como representar isso na linguagem matemática correta.

Nessa fase, foi importante a intervenção dos professores, pois houve a necessidade de explicar a forma matemática adequada de escrever a expressão que haviam determinado, explicitando que a representação matemática correta consistia em escrever entre parênteses o termo $(n-3)$, ou seja, seriam corretas as expressões: $(n-3) \times n$ ou $n \times(n-3)$. Essa intervenção dos professores também foi importante para esclarecer aos outros três alunos as generalizações que os colegas haviam determinado.

Após estabelecer a expressão $n \times(n-3)$, para a determinação do número de diagonais de um polígono, os participantes foram instigados a confirmarem a validade de sua conjectura para alguns polígonos. Para tanto, propomos a nona atividade, dividida em duas partes. A primeira consistia em comparar o número de diagonais de quatro polígonos, a partir de suas respectivas representações figurais, com demarcação e contagem de suas diagonais e a fórmula encontrada $n \times(n-3)$. 
A Figura 9 apresenta a tarefa realizada pelo aluno $C$. Nela, podemos observar que é possível perceber que a expressão $n \times(n-3)$ não determina o número de diagonais de um polígono, mas sim o dobro desse valor.

Figura 9 - Resposta do Aluno C

\begin{tabular}{|l|l|l|c|}
\hline Polígono & $\begin{array}{c}\text { Número } \\
\text { de lados }\end{array}$ & n.(n-3) & $\begin{array}{c}\text { Número de } \\
\text { diagonais }\end{array}$ \\
\hline & $4 .(4-3)=$ & \\
$4.5=4$ & 2 \\
\hline & $5 .(5-3)=$ & \\
\hline
\end{tabular}

Fonte: acervo dos autores (2017)

A segunda etapa da nona atividade consistiu em três questionamentos e foi elaborada com a intenção de orientar as comparações a serem realizadas pelos participantes. Na primeira questão, os alunos foram indagados se a expressão $n \times(n-3)$ determinaria o número de diagonais de cada polígono. Todos os participantes responderam que não.

A pergunta seguinte interpelava sobre a relação entre a expressão e o valor encontrado pela contagem direta. Apenas um aluno não respondeu corretamente, do restante, cinco indicaram que a expressão deveria ser dividida por 2 e três apontaram que a expressão determinava o dobro do número de diagonais, como indicamos na Figura 10, que apresenta as respostas elaboradas pelos alunos $\mathrm{C}$ e $\mathrm{E}$, respectivamente.

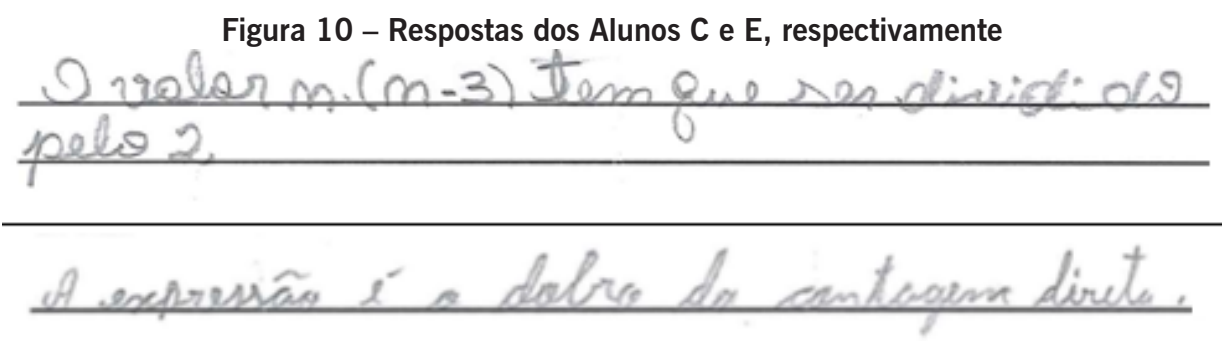

Fonte: acervo dos autores (2017)

0 terceiro questionamento era sobre a forma de corrigir a expressão $n \times(n-3)$ de modo a garantir que ela determinasse corretamente o número de diagonais de um polígono. Com excessão de um aluno, que não respondeu a questão, os demais apontaram a necessidade de dividir a expressão por 2, como exemplificado na Figura 11, encontrando então a resposta esperada: $\frac{n \times(n-3)}{2}$. 
Figura 11 - Resposta do Aluno H

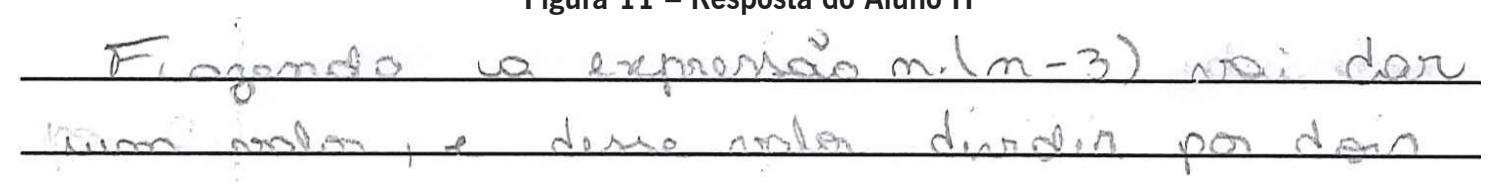

Fonte: acervo dos autores (2017)

Ao finalizar as três etapas da oficina, percebemos que os alunos conseguiram retomar conhecimentos relacionados aos elementos de polígonos, tais como lados, ângulos internos, vértices e diagonais, e construir novos, como a expressão para determinar o número de diagonais de um polígono convexo de $n$ lados.

Para concluir nossa investigação, realizamos um quarto momento, reservado para os alunos expressarem suas opiniões sobre a prática realizada. Para isso, foram propostos três questionamentos: (1) "Você gostou das atividades realizadas? Em caso afirmativo, de qual mais gostou?"; (2) "O que você aprendeu com as atividades trabalhadas hoje?" e (3) Você gostaria que houvesse mais atividades como essas? Justifique sua resposta".

Apenas um participante não respondeu afirmativamente a primeira pergunta. Os demais apontaram que gostaram das atividades realizadas, sendo que três destacaram que o que mais gostaram foi a confecção dos polígonos com as dobraduras.

Quanto ao que aprenderam, cinco alunos responderam ter aprendido a construir polígonos de uma forma diferente (por meio de dobraduras), dois salientaram que aprenderam como determinar a quantidade de diagonais de um polígono, um afirmou não ter aprendido nada e um evidenciou que aprendeu que tem muito a aprender sobre polígonos. 0 depoimento desse último participante nos chamou a atenção pelo senso crítico do aluno a respeito da sua aprendizagem.

Por fim, sobre o desejo de mais atividades práticas como a que realizamos, apenas um aluno respondeu que não queria outras do mesmo estilo, porque era muita coisa para se fazer. Esse aluno foi o mesmo que respondeu negativamente as outras questões. Os demais participantes responderam que gostariam de atividades semelhantes, sendo que cinco justificaram que atividades assim proporcionam revisão de conceitos já estudados e a construção de novos.

\section{Considerações finais}

Neste trabalho, buscamos apresentar e discutir se a utilização de materiais manipuláveis e atividades exploratórias possibilitam a construção de conceitos e a dedução de fórmulas matemáticas, em particular, relacionadas às diagonais de polígonos.

Ao finalizar as atividades, verificamos que o grupo participante alcançou o objetivo almejado, uma vez que a maioria dos alunos, com base na manipulação dos polígonos construídos e na realização das atividades exploratórias, compreendeu o conceito de diagonal de um polígono e conseguiu determinar a expressão matemática que fornece o total de diagonais de um polígono de lados.

Além disso, consideramos que o momento da prática destinado à construção dos polígonos com fitas de papel foi profícuo, pois possibilitou aos alunos manipular os entes geométricos em estudo, favorecendo a identificação dos elementos constituintes dos polígonos. Fato comprovado pelo entusiasmo demonstrado pelos participantes desde o início da investigação e pelos resultados apontados na avaliação que realizaram ao final da proposta.

Esperamos que a prática aqui descrita venha a contribuir com ações no futuro, as quais possam ser desenvolvidas por outros educadores. Além disso, almejamos que nosso trabalho também colabore com reflexões e discussões sobre o uso de materiais didáticos em sala de aula, em particular os materiais manipuláveis. 


\section{Referências}

BRASIL. Ministério da Educação. Base Nacional Comum Curricular. 2017. Disponível em: <http:// basenacionalcomum.mec.gov.br/images/BNCC_20dez_site.pdf>. Acesso em: 28 jan. 2018.

BULOS, Adriana Mascarenhas Mattos. 0 Ensino da Geometria nos Anos Iniciais do Ensino Fundamental. In: CONFERÊNCIA INTERAMERICANA DE EDUCAÇÃO MATEMÁTICA, 13., 2011, Recife/PE. Anais [...] Recife/PE: Universidade Federal de Pernambuco, 2011, p. 1-8.

CAMACHO, Mariana Sofia Fernandes Pereira. Materiais Manipuláveis no Processo de Ensino/ Aprendizagem da Matemática: Aprender explorando e construindo. Relatório de estágio de mestrado. 2012. Disponível em: <https://digituma.uma.pt/bitstream/10400.13/373/1/MestradoMarianaCamacho. pdf>. Acesso em: 16 maio 2018.

CARVALHO, Maria Aparecida da Silva de; CARVALHO, Ana Márcia Fernandes Tucci de. 0 ensino de geometria não euclidiana na educação básica. In: CONFERÊNCIA INTERAMERICANA DE EDUCAC̣ÃO MATEMÁTICA, 13, 2011, Recife/PE. Anais [...] Recife/PE: Universidade Federal de Pernambuco, 2011, p. 1-9.

DOLCE, Osvaldo; POMPEO, José Nicolau. Fundamentos da Matemática Elementar: Geometria Plana. Vol 9. 7. ed. São Paulo: Atual, 1995.

JANUÁRIO, Gilberto. Materiais Manipuláveis: Mediadores na (Re) construção de Significados Matemáticos. 2008. Disponível em: http://www.colegioglauciacosta.com.br/moodle/file.php/1/ Materiais_manipulaveis_mediadores_na_reconstrucao_de_significados_matematicos.PDF. Acesso em: 03 maio 2018.

LEIVAS, José Carlos Pinto; LARA, Débora da Silva a de; SOARES, Gabriel de Oliveira. Polígonos: dobra aqui, dobra ali e um objeto esquecido - o transferidor. Ensino e Tecnologia em Revista, Londrina, v. 1, n. 2, p. 209-225, jul./dez., 2017.

LORENZATO, Sérgio. 0 laboratório de ensino de matemática na formação de professores. São Paulo: Autores Associados, 2009.

MIRANDA, Vicente Carrión. Un Recurso para la Enseñanza de la Geometría. Educación Matemática. v. 5, n. 1, p. 11-45, abr., 1993. Disponivel em: <http://www.revista-educacion-matematica.org.mx/ descargas/vol5/vol5-1/vol5-1-2.pdf>. Acesso em: 20 ago. 2017.

PAIS, Luiz Carlos. Uma análise do significado da utilização de recursos didáticos no ensino da geometria. 2000. Disponível em: <http://www.ufrrj.br/emanped/paginas/conteudo_producoes/ docs_23/analise_significado.pdf>. Acesso em: 21 mar. 2019.

RÊGO, Rogéria Gaudencio do; RÊGO, Rômulo Marinho. Matematicativa. 4. ed. rev. Campinas, SP: Autores Associados, 2013.

SANTOS, Sandra Augusta. Explorações da linguagem escrita nas aulas de Matemática. In: LOPES, Celi Aparecida Espasandin; NACARATO, Adair Mendes. Escritas e leituras na educação matemática. Belo Horizonte: Autêntica, 2005. p. 127-141. 
USISKIN, Zalman. Resolvendo os dilemas permanentes da geometria escolar. In: LINDQUIST, Mary Montgomery; SHULTE, Albert P. (org.) Aprendendo e ensinando geometria. São Paulo: Atual, 1994, p. 21-39.

ZABALA, Antoni. A prática educativa: como ensinar. Tradução Ernani F. da Fonseca Rosa. Porto Alegre: ArtMed, 1998. 